\title{
Resenhas
}

\section{Processo motivacional na PSiCOLOGIA CONTEMPORÂNEA}

\author{
Boruchovitch, E. \& Bzuneck, J.A. (Orgs.) (2001). A Motivação do Aluno - \\ Contribuições da Psicologia Contemporânea. Petrópolis: Editora Vozes, 183 p.
}

$\mathbf{O}_{\mathrm{s}}$ apresentar para psicólogos educacionais, professores e educadores o estado da arte dessa área de conhecimento psicológico que é a motivação do aluno no seu contexto escolar. Eles se propuseram a propiciar uma ferramenta conceitual e atualizada, tendo como esteio uma vasta bibliografia, para se enfrentar o difícil problema de se motivar alunos para as atividades das diversas disciplinas escolares. Para tanto, selecionaram para esta obra alguns dos temas mais desenvolvidos na literatura contemporânea.

No primeiro capítulo, que tem um caráter introdutório, Bzuneck apresenta uma visão panorâmica dos estudos mais recentes sobre motivação no contexto escolar, seus problemas e linhas de solução. Salienta que foi especialmente a partir do início dos anos 1980 que se iniciou, em diversos países do mundo, um período de intensa pesquisa psicológica sobre esse tema e que perdura até o momento. O capítulo mostra detalhadamente os avanços em termos de conceituações e abordagens prevalentes na época atual, em comparação com períodos anteriores e esclarece que, antes de tudo, delineou-se a consciência de que a motivação em sala de aula deve ser tratada como um fenômeno e um problema distintos do que ocorre com a motivação humana em outros contextos. Na mesma linha, os estudos relatados trazem a marca de uma definida preocupação educacional. O capítulo apresenta os problemas motivacionais mais comuns em nossa realidade educacional e explora os vários aspectos do papel do professor em relação à sua tarefa de preveni-los, remediá-los, em suma, de motivar os alunos. Desta forma, esse capítulo inicial situa o leitor em relação à abrangência do tema e prepara o desenvolvimento dos capítulos seguintes.

Guimarães, no segundo capítulo, retoma dois con- ceitos clássicos: a motivação intrínseca e a extrínseca. A autora mostra as diferentes contribuições teóricas e o que se produziu mais recentemente que contribuíram para o refinamento do conceito de motivação intrínseca e para a compreensão dos fatores que a implementam ou prejudicam. Especificamente em relação aos motivadores extrínsecos, são destacadas as formas auto-reguladas de interação com os controles externos, bem como as exigências práticas para que se promova tal envolvimento com as atividades de aprendizagem.

O capítulo seguinte, assinado por Bzuneck, descreve a moderna teoria de metas de realização, que focaliza objetivos de elevado impacto motivacional. Tratase de metas no sentido qualitativo de programas mentais, ou esquemas, que orientam comportamentos e emoções. É mostrado como essa nova teoria tem interface com a teoria tradicional de McClelland e Atkinson, mas apresenta-se com novos contornos e significados. Por duas décadas, os estudos aí apresentados revelam que tais metas de realização (a de domínio, de performance ou de evitação do trabalho) representam uma explicação da direção e da qualidade dos esforços do aluno.

Além disso, os estudos têm mostrado como o desenvolvimento de cada uma dessas metas ocorre em função daquilo que se chama "currículo oculto" na sala de aula e na escola, um aspecto que tem forte apelo educacional. Isto é, a formação dessas orientações motivacionais depende substancialmente de certas modalidades do contexto imediato em que se realizam as atividades escolares. Como o professor se comporta em classe em relação às tarefas, como reage aos tipos de desempenho do aluno, que mensagens explícitas ou veladas ele transmite, eis aí alguns dos componentes do clima de sala de aula, desenvolvidos no ca- 
pítulo 4, de Guimarães, que afetam o desenvolvimento de uma ou outra daquelas metas em seus alunos.

Em síntese, esses três últimos capítulos formam um bloco de conteúdos intimamente ligados e que, em função das aplicações potenciais, abrangem amplo espectro educacional. Eles focalizam as duas linhas de pesquisa que, no momento, mais têm produzido resultados relevantes à compreensão da motivação do aluno e para o trabalho em classe: a que trata da relação entre o uso de recompensas externas com a motivação intrínseca e a que contempla as metas de realização, sendo o que mais fascina em relação a elas são as consequiências para as práticas educacionais que delas emanam e que têm sido vastamente focalizadas em pesquisas.

Os organizadores da obra selecionaram, além disso, três temas motivacionais específicos e sempre atuais, que correspondem aos três capítulos seguintes: a relação entre motivação e inteligência; as crenças de auto-eficácia do aluno; e a ansiedade nas situações de avaliação acadêmica.

Boruchovitch apresenta um texto atualizado sobre conceitos de inteligência, bem como o seu significado educacional. Em particular, é mostrado como a motivação do aluno se liga à capacidade para produzir os melhores resultados de aprendizagem. A crença sobre inteligência, como entidade fixa ou como passível de crescimento, é particularmente focalizada nos estudos sobre motivação em sala de aula.

Em parte ligado ao tema da inteligência, as crenças de auto-eficácia são abordadas no capítulo seguinte, de Bzuneck, que apresenta o conceito, os componentes, as origens e, sobretudo o significado motivacional dessa variável específica. Mas são também mostrados os limites da influência dessas crenças. Originada de propostas e pesquisas de Bandura, essa linha de estudos complementa e aperfeiçoa os conhecimentos relativos ao autoconceito e autopercepções de capacidade, tradicionalmente considerados no campo da motivação.
O terceiro tema específico tratado é o da ansiedade nas situações de avaliação na escola. Boruchovitch e Costa apresentam nesse capítulo o histórico de estudos sobre esse fenômeno, que culmina nos estudos mais recentes sobre ansiedade nas provas, que já conta com notável acumulação de conhecimentos sobre suas origens, componentes e métodos de tratamento.

Duas pesquisas brasileiras recentes são relatadas nos dois capítulos finais. A primeira, de Martini e Boruchovitch, retoma um enfoque que, tradicionalmente, tem sido muitas vezes adotado em pesquisas brasileiras, o das atribuições da causalidade. No presente estudo, os participantes eram crianças do Ensino Fundamental, expostas a situações hipotéticas de desempenho escolar que lhes diziam respeito. Os resultados mostraram as preferências de atribuições causais nas várias contingências apresentadas, assim como sua relação com gênero e série escolar. Com base numa literatura bem atualizada, as autoras comentam os dados obtidos, extraindo importantes conclusões educacionais.

A outra pesquisa, liderada por Sisto, compõe o último capítulo, focalizando um aspecto valorizado em estudos recentes, que é o das percepções dos alunos sobre a escola como um todo, bem como suas manifestações de satisfação com esse ambiente de aprendizagem. Os autores desenvolveram um instrumento de medida dessa satisfação, apresentando resultados relevantes para os educadores.

Todos os capítulos, bem estruturados e entrosados, consistem em leitura recomendada a profissionais e pesquisadores interessados no tema. Seus leitores encontrarão nesta livro excelente fonte de informações sobre aspectos teóricos e aplicados do tema Motivação. Seu conteúdo poderá, por um lado, instigar pesquisas que busquem a continuidade da investigação de questões nele apontadas, e, por outro, propiciar a derivação de práticas educativas nos diversos contextos educacionais.

Acácia Aparecida Angeli dos Santos Universidade São Francisco 